\title{
Opioid prescribing and adverse events in opioid-naive patients treated by emergency physicians versus family physicians: a population-based cohort study
}

\author{
Bjug Borgundvaag MD PhD, Shelley McLeod MSc, Wayne Khuu MPH, Catherine Varner MD MSc, \\ Mina Tadrous PharmD PhD, Tara Gomes PhD
}

\section{Abstract}

Background: Emergency physicians provide primary care to patients and often prescribe opioids for acutely painful self-limiting conditions. The objective of this study was to describe patterns of opioid prescribing by emergency physicians and family physicians and to explore the relation between setting of initiation of opioid treatment and adverse events over the subsequent 2 years.

Methods: This was a population-based cohort study using administrative data from Ontario. Opioid-naive patients aged 15-64 years who received an opioid prescription for noncancer pain from an emergency or family physician between Apr. 1, 2008, and Mar. 31, 2012 were eligible for inclusion.

Results: A total of 34713 and 45952 patients were initiated on an opioid by an emergency physicians and family physicians, respectively. Both emergency and family physicians most commonly prescribed codeine-containing products $(58.9 \%$ and $79.6 \%$ of prescriptions, respectively); however, emergency physicians were twice as likely as family physicians to prescribe higher-potency opioids (morphine, oxycodone, hydromorphone, fentanyl, meperidine) (both combination and single-agent preparations) (40.6\% v. $19.9 \%, \Delta=20.7,95 \%$ confidence interval $[\mathrm{Cl}] 20.0-21.3)$. Compared to patients in the family physician group, those in the emergency physician group received significantly higher daily dosages, a higher proportion were initiated on a daily dosage of $100 \mathrm{mg}$ of morphine equivalents (MEQs) or more, and had a hospital admission for opioid toxicity within 2 years $(0.5 \% \mathrm{v} .0 .3 \%, \Delta=0.2 \%$, $95 \% \mathrm{Cl} 0.1 \%-0.3 \%$ ). A higher proportion of patients in the family physician group than in the emergency physician group had dosage escalation beyond $199 \mathrm{mg}$ MEQs within 2 years $(0.7 \%$ v. $0.1 \%, \Delta=0.6 \%, 95 \% \mathrm{Cl} 0.5 \%-0.7 \%)$.

Interpretation: Codeine was the most common opioid prescribed by emergency and family physicians. Compared to patients prescribed opioids by family physicians, those prescribed opioids by emergency physicians received higher initial daily dosages and had an increased likelihood of opioid toxicity.

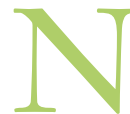
orth Americans consume nearly two-thirds of the opioids prescribed globally. ${ }^{1}$ In 2014 in Ontario (population 13 million), nearly 2 million people filled 9 million prescriptions for an opioid medication. ${ }^{2}$ Although opioid prescribing in North America has increased overall, the greatest growth in Ontario has been in highpotency opioids, with hydromorphone dispensing increasing by $70 \%$ between 2013 and $2015 .{ }^{2}$ Increasing prescription opioid use and higher dosages of these medications have been associated with substantial harm, including the development of opioid use disorder, toxicity, diversion and death. ${ }^{3-7}$

Family physicians are the single largest group of opioid prescribers in North America. $2,8,9$ Emergency physicians also provide primary care to patients and often prescribe opioids for acutely painful self-limiting conditions. ${ }^{10}$ As such, family physicians constitute the most appropriate prescriber comparison group for emergency physicians. The relative contribution to overall opioid prescribing by emergency and family

Competing interests: Tara Gomes has received unrestricted grant funding from the Ontario Ministry of Health and Long-Term Care (MOHLTC). Mina Tadrous has received support from the MOHLTC Health System Research Fund. No other competing interests were declared.

This article has been peer reviewed.

Correspondence to: Bjug Borgundvaag, bjug.borgundvaag@ sinaihealthsystem.ca

CMAJ Open 2018. DOI:10.9778/cmajo.20170151 
physicians in Canada remains unknown. Emergency department data from the United States indicate that opioid use increased $90 \%$ between 2001 and 2010, and that opioids were prescribed at discharge to almost $20 \%$ of patients. ${ }^{10-12}$ Although most emergency physicians likely consider opioid medications safe for the relief of acute pain and may therefore regard their role in the current opioid crisis to be limited to preventing diversion, recent reports suggest that opioids prescribed in the emergency department, especially to opioidnaive patients, are associated with substantial morbidity. ${ }^{13-15}$

In 2014-2015, there were 4779 hospital admissions due to opioid toxicity in Canada, representing a total of 38405 days of care provided in Canadian hospitals to patients admitted with a diagnosis of opioid toxicity. ${ }^{16}$ Patients admitted for opioid toxicity remained in hospital for an average of 8.0 days, longer than the stay for those admitted for a heart attack, pneumonia or hip replacement surgery. ${ }^{16}$

The primary objectives of this study were to describe and compare opioid-prescribing patterns by emergency and family physicians, and to explore the relation between setting of initiation of opioid prescribing and hospital admission for opioid toxicity and dosage escalation beyond $199 \mathrm{mg}$ morphine equivalents (MEQs).

\section{Methods}

\section{Setting}

We conducted a population-based cohort study of Ontario residents aged 15-64 years who were eligible for public drug coverage and started opioid treatment between Apr. 1, 2008, and Mar. 31, 2012. Public drug coverage among those less than 65 years of age is provided to residents receiving social assistance, disability support or home care services, those residing in long-term care homes and those with high drug costs relative to their income. All residents of Ontario are eligible for provincially funded universal health coverage, including physician services and hospital stays. The cohort of patients in this study represented about $10 \%$ of the total population of the Ontario aged 15-65 years.

\section{Data sources}

We used the Ontario Drug Benefit claims database to identify prescription drug claims for publicly funded opioids and other medications dispensed from retail pharmacies over the study period. We used the Registered Persons Database to determine patient demographic characteristics and vital statistics, and the Ontario Health Insurance Plan claims database to capture use of health care services, including visits to a family physician. We used the Canadian Institute for Health Information's National Ambulatory Care Reporting System, Discharge Abstract Database and Ontario Mental Health Reporting System to capture details on diagnoses and procedures occurring during emergency department visits, inpatient hospital stays and admissions to designated mental health hospital beds across Ontario, respectively. We used the Ontario Cancer Registry to identify patients with a past cancer diagnosis and the Institute for Clinical Evaluative Sciences (ICES) vali- dated databases of people with HIV infection, diabetes, arthritis, and Crohn's disease and colitis to identity patient comorbidities. Finally, we used the ICES Physician Database to determine physician characteristics, including prescriber specialty. These data sets were linked through unique encoded identifiers and analyzed at the ICES. Further details are available on the ICES website. ${ }^{17}$

\section{Identification of cohort}

We identified all new users of a prescription opioid (including codeine, oxycodone, fentanyl, morphine, hydromorphone and meperidine) to treat pain over the study period and defined a patient's index date as the date of their first opioid prescription. New users were defined as patients with no prescription for any prescription opioid in the year before their index date. We excluded people with missing patient identifiers, age or sex, those aged less than 15 years or more than 64 years at their index date, those with invalid death dates (i.e., death date before index date) and those who were not eligible for the Ontario Drug Benefit in the prior year (defined has having no prescriptions for any medication reimbursed by the Ontario Drug Benefit within 181-365 days before their index date). Finally, to restrict the cohort to patients using opioids for noncancer pain, we excluded people who had received palliative care services within 180 days before their index date or had a prior cancer diagnosis.

\section{Exposure}

The main exposure was the setting (emergency or primary care) in which a person received his or her first opioid prescription. This was determined by identifying all emergency department and family physician visits occurring on the index date or in the 2 days prior. Family physician visits were defined as any office visit to a family physician billed to the Ontario Health Insurance Plan. Patients who had only 1 visit to either the emergency department or a family physician on their index date or in the 2 days prior were classified accordingly. Patients who had visits to both the emergency department and a family physician on their index date or in the 2 days prior were classified as having received their prescription from a family physician if the prescriber's identification number on the prescription matched the family physician's identification number for the office visit; otherwise, the prescription was assumed to have originated from the emergency department. People who did not have any record of a visit to the emergency department or a family physician on the index date or in the 2 days prior were excluded. We also excluded patients whose dosage of their index opioid prescription was $200 \mathrm{mg}$ MEQs (a dosage associated with an increased risk of death ${ }^{5}$ ) or more because dosage escalation beyond this threshold was used as an outcome in this study and because it is highly unlikely that an opioid-naive patient would receive such a high initial dosage.

\section{Outcome}

To determine outcomes related to opioid dosage and toxicity, we followed patients from the date of their first prescription until death, end of follow-up (Mar. 31, 2014) or a maximum 
of 2 years, whichever came first. We identified the primary outcome, an opioid-related toxicity event, as an emergency department visit or inpatient hospital stay (acute or mental health related) with an admission diagnosis of opioid toxicity (International Classification of Diseases, 10th revision, codes T40.0-T40.4 or T40.6) during the follow-up period. The secondary outcome was defined as receipt of an opioid prescription with a daily dosage of $200 \mathrm{mg}$ MEQs or more within their period of continuous opioid use. For this outcome, we defined continuous opioid use as having filled a subsequent prescription for opioids within twice the days' supply of the previous prescription, and opioid discontinuation was added as a censoring criterion. If multiple opioid prescriptions were filled on 1 day, we summed the daily dosage of all prescriptions. To capture people who may have transitioned to obtaining opioids through cash payments or illicit means, we did not require patients to be continuous opioid users for our primary outcome.

\section{Patient characteristics}

We recorded patient characteristics including demographic characteristics (age, sex, income quintile and urban residence), history of treatment or diagnosis related to substance abuse disorders in the previous year (hospital visit for opioid toxicity, other drug toxicity, intentional self-harm and alcohol use disorder), mental health disorders in the previous 2 years and other medical comorbidities (osteoarthritis, rheumatoid arthritis, inflammatory bowel disease, HIV infection and diabetes). We measured use of health care services as the number of emergency department visits, physician office visits and inpatient hospital stays in the year before the index date. We identified previous use of antidepressants, antipsychotics, benzodiazepines, drugs for neuropathic pain, and other psychotropic and central nervous system depressants in the previous 180 days. We identified the 10 most common indications for initiation of opioid treatment in either exposure group using the main diagnosis code listed on the emergency department record (for emergency physician initiators) or closest physician billing (for family physician initiators) on the date of treatment initiation or in the 2 days before. Finally, we characterized index opioid use in several ways, including formulation (long-acting v. shortacting), specific drug and average daily dosage (in milligrams of MEQs).

\section{Statistical analysis}

We used descriptive statistics to summarize baseline characteristics using means and standard deviations, medians with interquartile ranges or frequencies. We compared betweengroup characteristics using standardized differences where appropriate. Group imbalance was defined as an absolute value of the standard deviation greater than $0.10 .{ }^{17} \mathrm{We}$ assessed between-group proportional differences using Pearson $\chi^{2}$ statistics and reported them with $95 \%$ confidence intervals (CIs). We used Cox proportional hazards regression models to estimate crude hazard ratios for dosage escalation and opioid toxicity while accounting for follow-up time and censored for death and end of follow-up. All analyses were performed with the use of SAS 9.4 (SAS Institute).

\section{Ethics approval}

This study was approved by the Research Ethics Board at Mount Sinai Hospital and the institutional review board at Sunnybrook Health Sciences Centre.

\section{Results}

A total of 176227 unique patients were first prescribed an opioid over the accrual period, 164881 of whom had noncancer-related pain (Figure 1). We excluded 83971 patients because we could not confidently attribute their index visit to a family physician or an emergency physician. The final

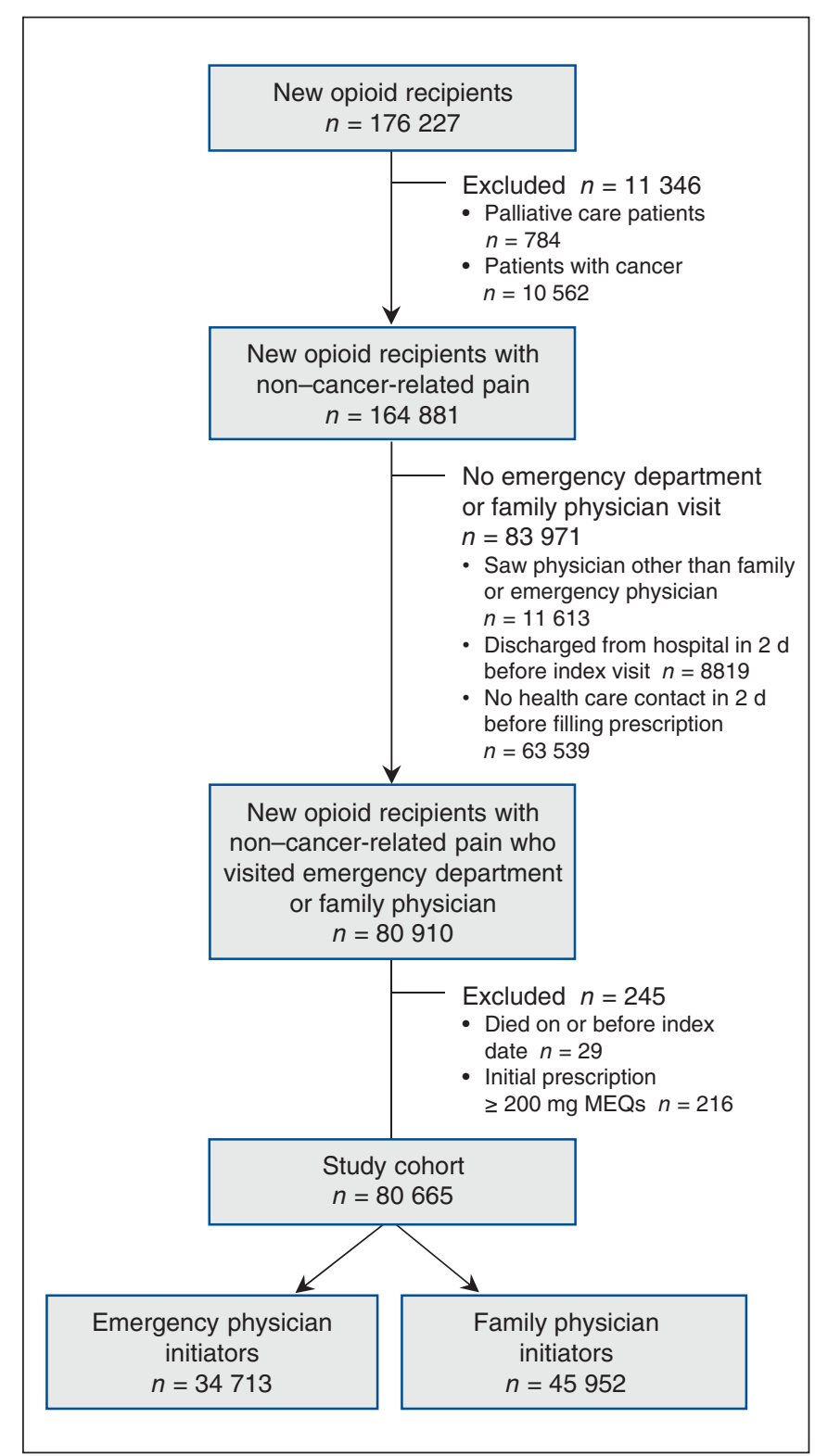

Figure 1: Flow diagram showing selection of study cohort. Note: $\mathrm{MEQ}=$ morphine equivalent. 
cohort consisted of 80665 patients who met our inclusion criteria, $34713(43.0 \%)$ in the emergency physician group and $45952(57.0 \%)$ in the family physician group.

Compared to patients in the emergency physician group, those in the family physician group tended to be older (mean $46.1 \mathrm{yr}$ v. $41.3 \mathrm{yr}$, standardized difference 0.35 ) and had fewer emergency department visits (mean 0.9 v. 1.9, standardized difference 0.31 ) and more family physician visits $(11.4$ v. 8.8 , standardized difference 0.29 ) in the year before their index visit (Table 1). Over half of patients in both groups had a history of psychiatric illness, and $20.9 \%$ had been prescribed benzodiazepines within 180 days before initiation of opioid treatment; $4693(13.5 \%)$ and $7952(17.3 \%)$ patients in the emergency physician and family physician groups, respectively, had active prescriptions for a benzodiazepine at the time their initial opioid prescription was obtained. No details were available on the number of deaths due to opioid poisoning; however, there was no difference in the death rate between the emergency physician and family physician groups over the course of the study $(n=30[0.1 \%]$ v. $n=91[0.2 \%]$, standardized difference 0.03 ).

Table 2 outlines the 10 most common diagnoses at the time of initiation of opioid treatment for the 2 groups. The top 3 diagnoses associated with emergency department initiation were back pain, abdominal pain (unspecified) and dental pain. For the family physician group, the top 3 diagnoses were back pain, arthralgia/joint pain and anxiety/psychiatric-related conditions.

There were considerable differences in the type of opioid prescribed between the 2 groups (Table 3). Although initiation of treatment with a long-acting opioid was rare in both groups, patients in the family physician group were more likely than those in the emergency physician group to be started on a long-acting opioid ( $2.3 \%$ v. $0.2 \%, \Delta=2.0,95 \%$ CI 1.9-2.2). Over $90 \%$ of patients in both groups were prescribed a combination product; however, emergency physicians were more likely than family physicians to prescribe oxycodone-containing combination products $(37.1 \% \mathrm{v}$. $16.5 \%, \Delta=20.6,95 \%$ CI 19.9-21.2). For patients started on single-agent products, emergency physicians were more likely to prescribe hydromorphone and morphine, whereas family physicians were more likely to prescribe codeine, fentanyl or oxycodone. Regardless of opioid type prescribed, patients in the emergency physician group were prescribed higher daily dosages than those in the family physician group (median $38 \mathrm{mg}$ MEQs v. $19 \mathrm{mg}$ MEQs, standardized difference 0.90), and a higher proportion were started on a daily dosage exceeding $99 \mathrm{mg}$ MEQs (3.1\% v. $0.9 \%, \Delta=2.1,95 \% \mathrm{CI}$ 1.9-2.3).

Table 4 details the crude rate of our primary (hospital admission for opioid toxicity) and secondary (dosage escalation to $200 \mathrm{mg}$ MEQs/d or more) outcomes. Patients in the emergency physician group were significantly more likely than those in the family physician group to have a hospital visit for opioid toxicity over the 2 -year follow-up period $(0.5 \%$ v. $0.3 \%, \Delta=0.2,95 \%$ CI $0.1-0.3)$. In a crude time-toevent analysis, initiation of opioid prescribing in the emer- gency department was associated with a 77\% increased hazard of opioid toxicity (hazard ratio 1.8, 95\% CI 1.4-2.2) compared to initiation by a family physician. In contrast, initiation of opioid treatment by a family physician was associated with an increased likelihood of dosage escalation beyond $199 \mathrm{mg}$ MEQs $(0.1 \%$ v. $0.7 \%, \Delta=0.6,95 \%$ CI $0.4-0.7)$. However, after we accounted for censoring (including treatment discontinuation), this difference was not statistically significant (hazard ratio $1.2,95 \%$ CI $0.9-1.7$ ).

\section{Interpretation}

In this population-based study spanning 6 years, we found that family physicians and emergency physicians contributed roughly equally to the total number of opioid prescriptions written for opioid-naive patients. However, we found significant differences in prescribing practices between these 2 provider groups, both in the potency of specific drugs prescribed and dosage at treatment initiation. Although emergency physician prescribing did not appear to be associated with dosage escalation to greater than $199 \mathrm{mg}$ MEQs/d, patients in this group experienced significantly more hospital admissions for opioid toxicity within 2 years.

In this study, almost $30 \%$ of all opioid prescriptions provided by emergency physicians exceeded a dosage of $49 \mathrm{mg}$ MEQs. Although there are no guidelines for opioid prescribing for acute pain, recently published Canadian prescribing guidelines for chronic noncancer pain recommend that the dosage of initial prescriptions not exceed $49 \mathrm{mg}$ MEQs (and in most cases should not exceed $89 \mathrm{mg}$ MEQs). ${ }^{18}$ Bohnert and colleagues $^{3}$ found a nearly fivefold increase in risk of opioid overdose death for patients with acute pain initiated on opioids at dosages exceeding $49 \mathrm{mg}$ MEQs, a risk that was equivalent to that among patients being treated for chronic pain. The subjective nature of pain makes it difficult to determine the appropriateness of prescribing based on diagnosis, but conditions that are obviously painful, such as extremity fractures, accounted for only $5 \%$ of the opioids prescribed in the emergency department setting in the current study. Conversely, the 5 most common emergency department diagnoses for which patients were prescribed an opioid (which accounted for $25 \%$ of all prescribing) were for conditions for which opioids are currently not recommended as first-line therapy (back pain, dental pain, pharyngitis). Back pain was the most common diagnosis for which opioids were prescribed by both emergency and family physicians, which suggests there is an opportunity to improve physician prescribing practice. Previous research has shown that functional outcomes are no better for patients with back pain treated with opioids than for those treated with nonsteroidal anti-inflammatory drugs (or other treatment modalities), and current recommendations do not endorse routine prescribing of opioids for this condition. ${ }^{18-20}$

Independent risk factors that have been associated opioidrelated harms include a history of psychiatric illness or substance use disorder, sleep disorders and the use of nonopioid medications with sedating properties, especially benzodiazepines. ${ }^{21-23} \mathrm{In}$ 


\begin{tabular}{|c|c|c|c|}
\hline \multirow[b]{2}{*}{ Characteristic } & \multicolumn{2}{|c|}{ Initiator; no. (\%) of patients* } & \multirow[b]{2}{*}{$\begin{array}{c}\text { Standardized } \\
\text { difference }\end{array}$} \\
\hline & $\begin{array}{l}\text { Emergency physician } \\
\qquad n=34713\end{array}$ & $\begin{array}{c}\text { Family physician } \\
n=45952\end{array}$ & \\
\hline \multicolumn{4}{|l|}{ Demographic } \\
\hline Age, mean \pm SD; yr & $41.32 \pm 14.0$ & $46.05 \pm 12.8$ & 0.40 \\
\hline Female sex & 20305 (58.5) & $28178(61.3)$ & 0.06 \\
\hline \multicolumn{4}{|l|}{ Income quintile } \\
\hline 1 & $14844(42.8)$ & $19822(43.1)$ & 0.01 \\
\hline 2 & $7742(22.3)$ & $10291(22.4)$ & 0.0 \\
\hline 3 & $5262(15.2)$ & $7092(15.4)$ & 0.01 \\
\hline 4 & $4073(11.7)$ & $5219(11.4)$ & 0.01 \\
\hline 5 & $2629(7.6)$ & $3331(7.2)$ & 0.01 \\
\hline Missing & $163(0.5)$ & $197(0.4)$ & 0.01 \\
\hline Rural location of residence & $5074(14.6)$ & $4312(9.4)$ & 0.20 \\
\hline \multicolumn{4}{|l|}{ Comorbidities } \\
\hline $\begin{array}{l}\text { Hospital visit for other drug toxicity } \\
\text { in prior year }\end{array}$ & $641(1.8)$ & $513(1.1)$ & 0.06 \\
\hline Intentional self-harm in prior year & $411(1.2)$ & $333(0.7)$ & 0.05 \\
\hline $\begin{array}{l}\text { Hospital visit for alcohol abuse in } \\
\text { prior year }\end{array}$ & $1553(4.5)$ & $1378(3.0)$ & 0.08 \\
\hline Osteoarthritis & $5954(17.2)$ & $12387(27.0)$ & 0.20 \\
\hline Rheumatoid arthritis & $488(1.4)$ & $860(1.9)$ & 0.04 \\
\hline Past injury & $6129(17.6)$ & $4927(10.7)$ & 0.20 \\
\hline HIV infection & $393(1.1)$ & $502(1.1)$ & 0.0 \\
\hline Diabetes & $6568(18.9)$ & $11505(25.0)$ & 0.20 \\
\hline Crohn's disease/colitis & $505(1.4)$ & $544(1.2)$ & 0.02 \\
\hline \multicolumn{4}{|l|}{ Mental health disorders } \\
\hline Affective disorder & $4162(12.0)$ & $4192(9.1)$ & 0.09 \\
\hline Anxiety or sleep disorder & $15339(44.2)$ & $20306(44.2)$ & 0.0 \\
\hline $\begin{array}{l}\text { Psychosis, agitation or related } \\
\text { disorder }\end{array}$ & $3893(11.2)$ & $3755(8.2)$ & 0.10 \\
\hline All other mental health disorders & $11698(33.7)$ & $14020(30.5)$ & 0.07 \\
\hline Any mental health disorder & $19780(57.0)$ & $26056(56.7)$ & 0.01 \\
\hline \multicolumn{4}{|c|}{ Use of health care services in prior year } \\
\hline $\begin{array}{l}\text { No. of emergency department visits, } \\
\text { mean } \pm \text { SD }\end{array}$ & $1.86 \pm 3.8$ & $0.90 \pm 2.1$ & 0.30 \\
\hline No. of physician visits, mean $\pm \mathrm{SD}$ & $8.80 \pm 8.3$ & $11.42 \pm 9.8$ & 0.30 \\
\hline Inpatient hospital stay & $3780(10.9)$ & $4069(8.8)$ & 0.07 \\
\hline \multicolumn{4}{|l|}{ Medication use in prior $180 \mathrm{~d}$} \\
\hline SSRI antidepressant & $6647(19.1)$ & $8393(18.3)$ & 0.02 \\
\hline Other antidepressant & $7149(20.6)$ & $10235(22.3)$ & 0.04 \\
\hline Antipsychotic & $5515(15.9)$ & $6260(13.6)$ & 0.06 \\
\hline Benzodiazepine & $6745(19.4)$ & $10145(22.1)$ & 0.07 \\
\hline $\begin{array}{l}\text { Other psychotropic drugs and } \\
\text { central nervous system depressants }\end{array}$ & $1031(3.0)$ & $996(2.2)$ & 0.05 \\
\hline Drugs for neuropathic pain & $379(1.1)$ & $665(1.4)$ & 0.03 \\
\hline Hydrocodone (cough suppressant) & $433(1.2)$ & $1109(2.4)$ & 0.09 \\
\hline
\end{tabular}


Table 2: Ten most common diagnoses recorded at time of initiation of opioid treatment, by prescription initiator

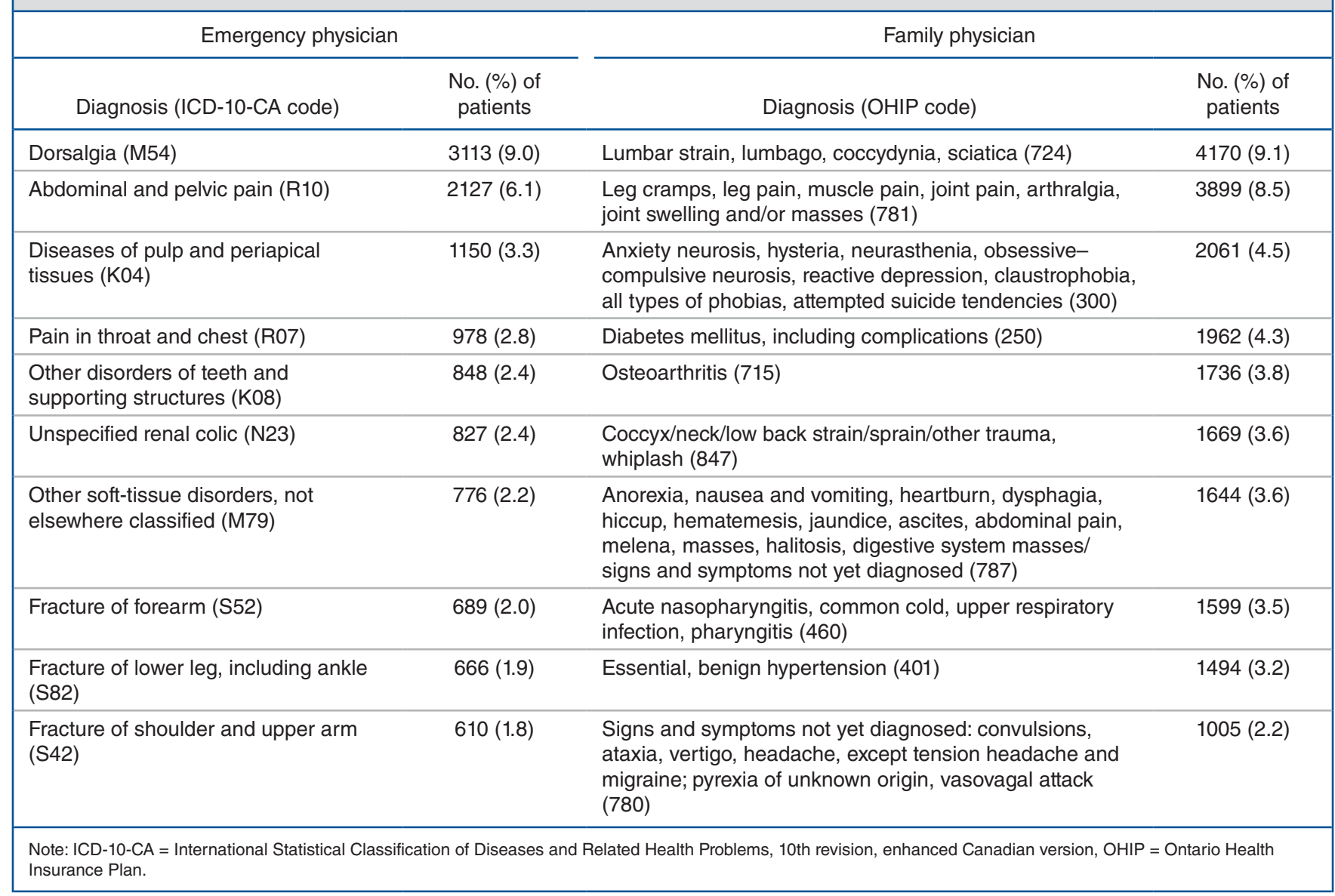

our study, a large number of patients in both the emergency physician and family physician groups had known risk factors associated with adverse outcomes related to opioid use. Nearly half of patients in both groups had documented anxiety or sleep disorders, and about one-fifth had received a prescription for a benzodiazepine within the previous 180 days (13.5\% and $17.3 \%$ of emergency physician and family physician patients, respectively, had active prescriptions for benzodiazepines when they were first prescribed opioids). A small proportion of patients in both groups had been admitted to hospital within the previous year for other drug toxicity or intentional self-harm. Although guidelines recognize these risks and suggest screening for them before opioid prescribing, further work is required to determine how to best manage pain and how to safely prescribe opioids (if at all) in populations with such a high prevalence of risk factors for adverse outcomes.

\section{Limitations}

This study has several limitations. Although all Ontarians have universal access to health care services, prescription drug coverage for those less than 65 years of age is generally restricted to socioeconomically disadvantaged people, and, therefore, our findings may not be generalizable to other patients. The opioid prescriptions included in this study represent only the volume of prescriptions that were filled by patients; we did not have information on prescriptions that were written but never filled by a pharmacy. Similarly, we estimated the daily opioid dosage in milligrams of MEQs from filled prescriptions reimbursed by the public drug program and did not account for overlapping prescriptions (unless both prescriptions were dispensed on the same day), drugs obtained illicitly or those paid for with cash. Therefore, the estimates of daily opioid dosage may be underestimates of the true daily dosage of opioids used by this cohort. Also, we report crude associations with our outcomes to assess overall differences in risks without taking into account differences in patient populations, since this will give a sense of the relative contribution of each prescriber setting to these outcomes. Because the aim of this investigation was to provide a basic description of patterns of opioid prescribing by emergency and family physicians and to explore the relation between initiation of opioid treatment, setting and subsequent opioid toxicity and dosage escalation, we did not adjust for independent factors associated with toxicity.

It is well known that patients with concurrent psychiatric conditions are at increased risk for adverse outcomes related to opioid prescribing, and current Canadian guidelines recommend against opioid prescribing until the active psychiatric disorder has been stabilized. ${ }^{24}$ Our observation that psychiatric conditions were a common cause for opioid prescribing by 


\begin{tabular}{|c|c|c|c|}
\hline \multirow[b]{2}{*}{ Variable } & \multicolumn{2}{|c|}{ Initiator; no. (\%) of patients* } & \multirow[b]{2}{*}{$\begin{array}{c}\text { Standardized } \\
\text { difference† }\end{array}$} \\
\hline & $\begin{array}{l}\text { Emergency } \\
\text { physician }\end{array}$ & $\begin{array}{l}\text { Family } \\
\text { physician }\end{array}$ & \\
\hline$>1$ prescription dispensed & $217(0.6)$ & $339(0.7)$ & 0.01 \\
\hline \multicolumn{4}{|l|}{ Formulation } \\
\hline Long-acting & $87(0.2)$ & $1048(2.3)$ & 0.18 \\
\hline Short-acting & 34598 (99.7) & 44779 (97.4) & 0.19 \\
\hline Both & $28(0.1)$ & $125(0.3)$ & 0.05 \\
\hline \multicolumn{4}{|l|}{ Opioid type } \\
\hline 2 different opioids & $183(0.5)$ & $245(0.5)$ & 0.0 \\
\hline \multicolumn{4}{|l|}{1 opioid } \\
\hline Combination product & 31991 (92.2) & 41941 (91.3) & 0.03 \\
\hline Codeine combination & 20117 (62.9) & 35005 (83.5) & 0.48 \\
\hline Oxycodone combination & $11874(37.1)$ & $6936(16.5)$ & 0.48 \\
\hline Single-agent products & $2539(7.3)$ & $3766(8.2)$ & 0.03 \\
\hline Codeine & $328(12.9)$ & $1563(41.5)$ & 0.68 \\
\hline Morphine & $804(31.7)$ & $592(15.7)$ & 0.38 \\
\hline Fentanyl & $\leq 5 \ddagger$ & $89(2.4)$ & $>0.1$ \\
\hline Oxycodone & $33(1.3)$ & $394(10.5)$ & 0.40 \\
\hline Hydromorphone & $1128(44.4)$ & $813(21.6)$ & 0.50 \\
\hline Meperidine & $241-245 \ddagger$ & $315(8.4)$ & $<0.1$ \\
\hline \multicolumn{4}{|l|}{ Dosage, MEQs/d } \\
\hline Median (IQR) & $38(25-50)$ & $19(13-32)$ & 0.90 \\
\hline$<20 \mathrm{mg}$ & $5782(16.6)$ & 23596 (51.3) & 0.79 \\
\hline $20-49 \mathrm{mg}$ & $19123(55.1)$ & $17684(38.5)$ & 0.34 \\
\hline 50-99 mg & 8739 (25.2) & $4238(9.2)$ & 0.43 \\
\hline $100-199 \mathrm{mg}$ & $1069(3.1)$ & $434(0.9)$ & 0.15 \\
\hline \multicolumn{4}{|c|}{$\begin{array}{l}\text { Note: IQR = interquartile range, MEQ = morphine equivalent. } \\
\text { "Except where noted otherwise. } \\
\text { tImbalance defined as absolute value greater than } 0.10 \text { (small effect size). } \\
\text { fln cases in which the number in the cell is less than } 6 \text {, this number has been suppressed to ensure confidentiality. } \\
\text { In cases in which only } 1 \text { record is being suppressed, another record has been suppressed to provide a range in } \\
\text { order to avoid residual disclosure. }\end{array}$} \\
\hline
\end{tabular}

family physicians requires further investigation. We were not able to determine the cause for these prescriptions; however, since physicians can apply only a single diagnostic code to a visit, it is possible that a patient seen for a primary psychiatric condition had a concurrent painful condition or that an underlying psychiatric condition was felt to result in a somatic pain complaint. Finally, we were unable to determine whether opioid-related emergency department visits and hospital admissions were a result of prescribed or nonprescribed opioids.

\section{Conclusion}

In this cohort of opioid-naive patients, codeine was the most common opioid analgesic prescribed by emergency and family physicians, either in combination with another product or as a single agent. Patients initiated on opioids by emergency phy- sicians were prescribed higher initial daily dosages and had a higher likelihood of subsequent opioid toxicity events than were patients started on opioids by family physicians. Our findings suggest that emergency physician prescribing contributes substantially to hospital admissions related to opioid toxicity and support a recommendation for opioid prescribing guidelines for acute pain. Future study should attempt to elucidate what factors are associated with a higher risk of subsequent hospital admission for opioid toxicity. Creation of physician-accessible registries would be useful to monitor opioid prescribing and dispensing, inform clinical practice and identify patients at high risk who may benefit from early interventions. However, in the absence of clear guidance for acute opioid prescribing, such repositories will do little to protect opioid-naive patients from potential harms. 


\begin{tabular}{|c|c|c|c|}
\hline Outcome & $\begin{array}{l}\text { Emergency } \\
\text { physician }\end{array}$ & $\begin{array}{l}\text { Family } \\
\text { physician }\end{array}$ & $p$ value \\
\hline \multicolumn{4}{|l|}{ Opioid toxicity } \\
\hline No. (\%) of patients & $172(0.5)$ & $129(0.3)$ & - \\
\hline Rate per 100 person-years & 0.25 & 0.14 & - \\
\hline Hazard ratio $(95 \% \mathrm{Cl})$ & $1.77(1.41-2.22)$ & Reference & $<0.001$ \\
\hline \multicolumn{4}{|l|}{ Dosage escalation } \\
\hline No. (\%) of patients & $46(0.1)$ & $301(0.7)$ & - \\
\hline Rate per 100 person-years & 6.19 & 7.67 & - \\
\hline Hazard ratio $(95 \% \mathrm{Cl})$ & $1.25(0.91-1.72)$ & Reference & $>0.05$ \\
\hline
\end{tabular}

\section{References}

1. Report of the International Narcotics Control Board on the availability of internationally controlled drugs: ensuring adequate access for medical and scientific purposes. New York: United Nations, 2011.

2. Health Analytics Branch, Health System Information Management Division, and Drug Program Policy and Strategy Branch, Ontario Public Drug Programs Division, Ministry of Health and Long-Term Care. Ontario narcotics atlas. Toronto: Ministry of Health and Long-Term Care; 2016.

3. Bohnert AS, Valenstein M, Bair MJ, et al. Association between opioid prescribing patterns and opioid overdose-related deaths. FAMA 2011;305:1315-21.

4. Centers for Disease Control and Prevention (CDC). CDC grand rounds: prescription drug overdoses - a U.S. epidemic. MMWR Morb Mortal Wkly Rep 2012;61:10-3.

5. Gomes T, Mamdani MM, Dhalla IA, et al. Opioid dose and drug-related mortality in patients with nonmalignant pain. Arch Intern Med 2011;171:686-91.

6. Paulozzi LJ, Zhang K, Jones CM, et al. Risk of adverse health outcomes with increasing duration and regularity of opioid therapy. 7 Am Board Fam Med 2014;27:329-38.

7. Shah A, Hayes CJ, Martin BC. Characteristics of initial prescription episodes and likelihood of long-term opioid use - United States, 2006-2015. MMWR Morb Mortal Wkly Rep 2017;66:265-9.

8. Ringwalt C, Gugelmann H, Garrettson M, et al. Differential prescribing of opioid analgesics according to physician specialty for Medicaid patients with chronic noncancer pain diagnoses. Pain Res Manag 2014;19:179-85.

9. Porucznik CA, Johnson EM, Rolfs RT, et al. Specialty of prescribers associated with prescription opioid fatalities in Utah, 2002-2010. Pain Med 2014;15:73-8.

10. Hoppe JA, Nelson LS, Perrone J, et al.; Prescribing Opioids Safely in the Emergency Department (POSED) Study Investigators. Opioid prescribing in a cross section of US emergency departments. Ann Emerg Med 2015;66:253-9.

11. Kea B, Fu R, Lowe RA, et al. Interpreting the National Hospital Ambulatory Medical Care Survey: United States emergency department opioid prescribing, 2006-2010. Acad Emerg Med 2016;23:159-65.

12. Mazer-Amirshahi M, Mullins PM, Rasooly I, et al. Rising opioid prescribing in adult U.S. emergency department visits: 2001-2010. Acad Emerg Med 2014;21:236-43.

13. Barnett ML, Olenski AR, Jena AB. Opioid-prescribing patterns of emergency physicians and risk of long-term use. NEngl 7 Med 2017;376:663-73.

14. Butler MM, Ancona RM, Beauchamp GA, et al. Emergency department prescription opioids as an initial exposure preceding addiction. Ann Emerg Med 2016;68:202-8

15. Hoppe JA, Kim H, Heard K. Association of emergency department opioid initiation with recurrent opioid use. Ann Emerg Med 2015;65:493-99.e4.

16. Canadian Institute for Health Information; Canadian Centre on Substance Abuse. Hospitalizations and emergency department visits due to opioid poisoning in Canada. Ottawa: Canadian Institute for Health Information; 2016.

17. Working with ICES data. Toronto: Institute for Clinical Evaluative Sciences. Available: https://www.ices.on.ca/Data-and-Privacy/ICES-data/Working -with-ICES-Data (accessed 2018 Jan. 18).

18. Abdel Shaheed C, Maher CG, Williams KA, et al. Efficacy, tolerability, and dose-dependent effects of opioid analgesics for low back pain: a systematic review and meta-analysis. 7AMA Intern Med 2016;176:958-68.

19. Deyo RA, Von Korff M, Duhrkoop D. Opioids for low back pain. BM7 2015; 350:g6380.

20. Friedman BW, Dym AA, Davitt M, et al. Naproxen with cyclobenzaprine, oxycodone/acetaminophen, or placebo for treating acute low back pain: a randomized clinical trial. $7 A M A$ 2015;314:1572-80.
21. Boscarino JA, Rukstalis M, Hoffman SN, et al. Risk factors for drug dependence among out-patients on opioid therapy in a large US health-care system. Addiction 2010;105:1776-82.

22. Cheatle MD, Webster LR. Opioid therapy and sleep disorders: risks and mitigation strategies. Pain Med 2015;16(Suppl 1):S22-6.

23. Paulozzi LJ. Prescription drug overdoses: a review. 7 Safety Res 2012;43:283-9.

24. Busse JW, Craigie S, Juurlink DN, et al. Guideline for opioid therapy and chronic noncancer pain. CMA7 2017;189:E659-66.

Affiliations: Division of Emergency Medicine (Borgundvaag, McLeod, Varner), Department of Family and Community Medicine, University of Toronto; Schwartz/Reisman Emergency Medicine Institute (Borgundvaag, McLeod, Varner), Mount Sinai Hospital; Li Ka Shing Knowledge Institute (Tadrous), St. Michael's Hospital; Institute for Clinical Evaluative Sciences (Khuu, Gomes); Leslie Dan Faculty of Pharmacy (Tadrous, Gomes), University of Toronto, Toronto, Ont.

Contributors: All of the authors contributed to the conception and design of the study, acquired, analyzed and interpreted the data, drafted and revised the manuscript, gave final approval of the version to be published and agreed to be accountable for all aspects of the work.

Funding: This study was funded through a Janus Research Grant from the College of Family Physicians of Canada. Funding was also provided by the Ontario Drug Policy Research Network, which is supported by grants from the Ontario Ministry of Health and Long-Term Care (MOHLTC) and the Ontario Strategy for Patient-Oriented Research Support Unit. The work was also supported by the Institute for Clinical Evaluative Sciences, which is funded by an annual grant from the MOHLTC.

Disclaimer: The opinions, results and conclusions reported in this article are those of the authors and are independent from the funding sources. No endorsement by the Institute for Clinical Evaluative Sciences, the Ontario Strategy for Patient-Oriented Research Support Unit or the Ontario Ministry of Health and Long-Term Care is intended or should be inferred. Parts of this material are based on data and information provided by Cancer Care Ontario (CCO). The opinions, results, view and conclusions reported in this paper are those of the authors and do not necessarily reflect those of CCO. No endorsement by CCO is intended or should be inferred. Parts of this material are based on data and information compiled and provided by the Canadian Institute for Health Information (CIHI). However, the analyses, conclusions, opinions and statements expressed herein are those of the authors and not necessarily those of the CIHI.

Acknowledgement: The authors thank IMS Brogan for use of their Drug Information Database.

Supplemental information: For reviewer comments and the original submission of this manuscript, please see www.cmajopen.ca/content/6/1/ E110/suppl/DC1. 